\author{
Е.В. Шмаков
}

\title{
ФИЗИЧЕСКАЯ РЕАБИЛИТАЦИЯ ЮНЫХ СПОРТСМЕНОВ С МИОПИЕЙ СЛАБОЙ СТЕПЕНИ
}

\begin{abstract}
Аннотация. Адекватные физические нагрузки и физическая реабилитация занимают важное место в комплексе мер по профилактике близорукости и ее прогрессирования, поскольку физические упражнения способствуют общему укреплению организма и активизации его функций. Специальные физические упражнения благоприятно влияют на показатели физической подготовленности и двигательных тестов, а также на формирование рефракции глаза у детей. Целью данной работы явилась оценка влияния программы физической реабилитации на показатели физической подготовленности и двигательных тестов у юных спортсменов с миопией слабой степени. Для определения уровня физической подготовленности применялись контрольные упражнения, включенные в нормативно-методические документы ВНИИФКа. Для характеристики физической подготовленности юных спортсменов были выбраны следующие тесты: бег 30 м, челночный бег 3х30, наклон вперед из исходного положения сидя, метание набивного мяча (3 кг) из-за головы, 6-минутный бег, поднимание туловища из положения лежа за 30 с. В исследовании приняли участие 140 детей в возрасте от 8 до 15 лет с миопией слабой степени и спазмом аккомодации. В экспериментальную группу вошли 110 детей, у которых миопия слабой степени была выявлена в 44\% случаев, а спазм аккомодации - в 56\% случаев. Контрольная группа насчитывала 30 человек, у которых миопия слабой степени была выявлена в 46\% случаев, а спазм аккомодачии - в 54\% случаев. Весь комплекс упражнений проводился в качестве дополнительного к тренировочному процессу. Дети из ЭГ выполняли упражнения для воспитания силовой выносливости мыши туловища и другие упражнения для формирования осанки; адаптированные игры или ритмическую гимнастику. Анализируя динамику показателей физической подготовленности и двигательных тестов детей со слабой степенью миопии и спазмом аккомодации, можно утверждать о положительном влиянии применяемой программы на повышение функциональных возможностей органов дыхания и кровообращения, а также адаптационных резервов сердечно-сосудистой и дыхательной систем.
\end{abstract}

Ключевые слова: педагогика, физическая реабилитация, миопия, юные спортсмены, двигательные тесты, физическая подготовленность, нагрузки, коррекция, компенсация, развитие.

а последние годы в нашей стране наблюдается тенденция к росту частоты близорукости у детей школьного возраста ${ }^{1}$. Исследования М.С. Бажукова (2008), С.А. Обрубова, В.М. Делягина, М.Ю. Демидовой, Н.С. Учаевой (2006), А.А. Мамонтов, О.В. Яловенко (2013) и др. показали, что изменения здоровья детей и подростков тесно взаимосвязаны с функциями органа зрения, внутренних органов, нервной системы и позвоночника.

Адекватные физические нагрузки и физическая реабилитация должны занять важное место в

1 Аветисов Э.С. Близорукость. 2-е изд., перераб. и доп. М., 2002. $284 \mathrm{c}$. комплексе мер по профилактике близорукости и ее прогрессирования, поскольку физические упражнения способствуют общему укреплению организма и активизации его функцийㄹ.

Специальные физические упражнения благоприятно влияют на показатели физической подготовленности и двигательных тестов, а также на формирование рефракции глаза у детей ${ }^{3}$.

\footnotetext{
2 Там же; Ахмадуллина И.А. Физическое воспитание слабовидящих учащихся среднего специального учебного заведения: автореф. дисс. ... канд. пед. наук. Набережные Челны, 2011. 255 c.

Myrowitz E.H. Juvenile myopia progression, risk factors and interventions. Saudi J Ophthalmol. 2012. Jul;26(3):293-7; Wall-
} 
Целенаправленные физические упражнения являются мощным средством коррекции и компенсации недостатков в физическом и функциональном развитии детей с миопией ${ }^{4}$.

Целью данной работы явилась оценка влияния программы физической реабилитации на показатели физической подготовленности и двигательных тестов у юных спортсменов с миопией слабой степени.

\section{Методы исследования.}

Для определения уровня физической подготовленности применялись контрольные упражнения, включенные в общероссийскую систему мониторинга детей, подростков и молодежи согласно современным научным данным теории и методикам детско-юношеского спорта, а также нормативно-методическим документам ВНИИФКа 5 .

Для характеристики физической подготовленности юных спортсменов были выбраны следующие тесты: бег 30 м (с), челночный бег $3 \times 30$ (c), наклон вперед из исходного положения сидя (см); метание набивного мяча (3 кг) из-за головы (м); 6-минутный бег (м), поднимание туловища из положения лежа за 30 с (кол-во раз).

Общий уровень физической подготовленности (ОУФИ) рассчитывали по формуле:

ОУФП $=[\Sigma(\mathrm{Pi}-\mathrm{HBПі}) / \mathrm{HBПi}] / 4$,

где $\mathrm{Pi}$ - индивидуальный результат по каждому тесту, НВПі - возрастной норматив по тому же тесту.

При исследовании двигательных тестов выполнялись тест на динамическую координацию,

ine J.J., Lindsley K., Vedula S.S., Cotter S.A., Mutti D.O., Twelker J.D. Interventions to slow progression of myopia in children / Cochrane Database Syst Rev. 2011. Dec 7;(12):CD004916.

4 Deng L., Gwiazda J., Manny R.E., Scheiman M., Weissberg E., Fern K.D., Weise K. Limited change in anisometropia and anisoaxial length over 13 years in myopic children enrolled in the correction of myopia evaluation trial. / Invest Ophthalmol Vis Sci. 2014. Apr 3;55(4):2097-105; Lin Z., Vasudevan B., Jhanji V., Gao T.Y., Wang N.L., Wang Q., Wang J., Ciuffreda K.J., Liang Y.B. Eye exercises of acupoints: their impact on refractive error and visual symptoms in Chinese urban children / BMC Complement Altern Med. 2013. Nov 7;13:306.

5 Балашова Н.Н., Левшина Г.П. и др. Допустимые уровни тренировочных и соревновательных нагрузок для учащихся учебно-тренировочных групп ДЮСШ и СДЮСШОР: Методические рекомендации. М., 1989. 22 с.; Никитушкин В.Г., Квашук П.В., Бауэр В.Г. Организационно-методические основы подготовки спортивного резерва. М.: Советский спорт, 2005. 232 c. тест на координацию движений и двигательную память, тест на пространственную ориентацию, теппинг-тест.

В исследовании приняли участие 140 детей в возрасте от 6 до 15 лет с миопией слабой степени. В экспериментальную группу вошли юные пловцы, борцы и легкоатлеты в возрасте 8-15 лет. Всего 110 детей, из них 62 девочки и 48 мальчиков. У детей экспериментальной группы миопия слабой степени была выявлена в 44\% случаев, а спазм аккомодации - в 56\% случаев.

Контрольная группа (КГ) насчитывала 30 человек (16 девочек и 14 мальчиков) соответствующего пола, возраста. У детей контрольной группы миопия слабой степени была выявлена в 46\% случаев, а спазм аккомодации - в 54\% случаев.

Дети из экспериментальной группы (ЭГ) осваивали разработанную комплексную программу физической реабилитации, состоящую из трех блоков. Продолжительность программы составила 9 месяцев.

Для сравнения была набрана группа здоровых детей, идентичная по поло-возрастным и спортивным характеристикам с детьми из экспериментальной и контрольной групп, в размере 30 человек.

Весь комплекс упражнений проводился в качестве дополнительного к тренировочному процессу.

Дети из ЭГ выполняли упражнения для воспитания силовой выносливости мышц туловища и другие упражнения для формирования осанки; адаптированные игры или ритмическую гимнастику.

Во время динамического часа (продолжительностью 40-45 мин.) проводились специальные упражнения для тренировки аккомодации и наружных мышц глаза, специальные зрительные игры, спортивные и подвижные игры по общим правилам (заменяемы адаптированными), упражнения для формирования правильной осанки, включая статические силовые.

Перед началом тренировки юными спортсменами выполнялись специальные упражнения для глаз и упражнения на осанку, что позволяло снимать утомление глаз, умственное и позное утомление и улучшало гемодинамику головы и, в частности, глаз.

Для достижения рационального эффекта в тренировочном процессе необходимо было соблюдать правильную дозировку статических и динамических упражнений. 


\section{Профессиональная психология}

Выполняющиеся статические и динамические упражнения для мышц спины, шеи, брюшного пресса способствовали развитию статической и динамической силовой выносливости, улучшению гемодинамики в мышцах, голове, глазах. Силовые упражнения статические и динамические чередовались со специальными упражнениями для глаз, тренирующие внутренние и наружные мышцы глаза.

При выполнении дыхательных упражнений оказывалось воздействие на внутричерепное давление и кровоснабжение глаза и мышц глаза.

\section{Результаты.}

Физическая подготовленность является одним из ведущих критериев при распределении детей в группы для занятий различными видами спорта.

До эксперимента показатели физической подготовленности детей контрольной и экспериментальной групп достоверно не отличались (p>0,05). После выполнения программы физической реабилитации отмечена достоверность различий между детьми контрольной и экспериментальной групп (таблица 1).

Наиболее значительные изменения отмечались в экспериментальной группе детей, в которой выполнялась программа физической реабилитации, что подтверждается статистически достоверной положительной динамикой по всем исследуемым показателям физической подготовленности (таблица 1).

Сравнительный анализ результатов выполнения контрольного упражнения «Бег 30 м» до и после эксперимента показал, что у девочек и мальчиков экспериментальной группы коэффициент прироста составляет 4,39\% и 4,91\%, у девочек и мальчиков контрольной группы - 1,34\% и 1,22\% соответственно.

Сравнительный анализ результатов выполнения контрольного упражнения «Челночный бег 3х30 м» до и после эксперимента показал, что у девочек и мальчиков экспериментальной группы данный показатель улучшился по сравнению с исходным на 4,99\% и 7,85\%, у девочек и мальчиков контрольной группы - на 2,13\% и 1,51\% соответственно.

Сравнительный анализ результатов выполнения наклона вперед из исходного положения сидя показал, что у девочек и мальчиков экспериментальной группы данный показатель возрос в среднем на 75,65\% и 72,96\%, у девочек и мальчи- ков контрольной группы - на 8,41\% и 7,52\% соответственно.

Анализ результатов метания набивного мяча из-за головы выявил, что у девочек и мальчиков экспериментальной группы данный показатель вырос в среднем на 73,23\% и 80,48\%, у девочек и мальчиков контрольной группы - на 6,32\% и 7,52\% соответственно.

Анализ 6-минутного бега учащихся выявил, что по окончании эксперимента пробегаемое за 6 минут расстояние у девочек и мальчиков с миопией экспериментальной группы увеличилось в среднем на $15,15 \%$ и 11,34\%, у девочек и мальчиков контрольной группы - на 3,12 \% и 7,40\% соответственно.

Количество подтягиваний и поднимания туловища из положения лежа у девочек и мальчиков с миопией экспериментальной и контрольной групп увеличилось по окончании эксперимента в среднем на $13,54 \%$ и $17,47 \%, 8,07 \%$ и 2,30\% соответственно.

Согласно анализу результатов исследования показатели коэффициента динамики результатов физической подготовленности достоверно выше у девочек и мальчиков экспериментальной группы $(\mathrm{p}<0,05)$.

Наиболее значительный прирост показателей физической подготовленности у детей экспериментальной группы выявлен по показателям в наклоне из исходного положения сидя, поднимании туловища из положения лежа и 6-минутный бег, что объясняется использованием в программе упражнений силовой направленности и упражнений на аэробную выносливость.

По показателям уровня физической подготовленности после проведения программы среди мальчиков и девочек ЭГ значительно уменьшился процент детей, имеющих хороший уровень физической подготовленности (с 71\% до $62 \%$ у мальчиков и с 78\% до $58 \%$ у девочек соответственно) и полностью исчез удовлетворительный уровень физической подготовленности. По нашему предположению это произошло за счет перемещения детей из группы, обладающих удовлетворительным уровнем физической подготовленности в группу детей с хорошим и отличным уровнем развития уровня физической подготовленности.

При этом соответственно значительно подрос отличный уровень физической подготовленности как среди мальчиков, так и среди девочек (таблица 2). 


\section{Психология и психотехника 7(70) • 2014}

Таблица 1.

Динамика показателей физической подготовленности обследуемых детей $(\mathrm{X} \pm \delta)$

\begin{tabular}{|c|c|c|c|c|c|c|c|}
\hline \multirow{2}{*}{ Показатели } & \multicolumn{2}{|c|}{ Здоровые дети } & \multicolumn{2}{|c|}{ ЭГ } & \multicolumn{2}{|c|}{$\mathrm{K \Gamma}$} & \multirow{2}{*}{$\mathbf{P}$} \\
\hline & до & после & до & после & до & после & \\
\hline \multicolumn{8}{|c|}{ Мальчики } \\
\hline бег 30 м (c) & $5,96 \pm 0,37$ & $5,81 \pm 0,32$ & $6,01 \pm 0,08$ & $5,21 \pm 0,02$ & $5,58 \pm 0,24$ & $5,16 \pm 0,21$ & $p<0,05$ \\
\hline $\begin{array}{l}\text { челночный бег } \\
3 \times 30 \text { (c) }\end{array}$ & $19,66 \pm 0,38$ & $18,35 \pm 0,26$ & $23,51 \pm 0,2$ & $20,44 \pm 0,16$ & $23,1 \pm 0,52$ & $22,00 \pm 0,48$ & $p<0,05$ \\
\hline $\begin{array}{c}\text { наклон вперед } \\
\text { из исходного } \\
\text { положения сидя (см) }\end{array}$ & $12,22 \pm 0,38$ & $15,56 \pm 0,53$ & $10,6 \pm 0,09$ & $12,50 \pm 0,38$ & $11,14 \pm 0,18$ & $11,98 \pm 0,11$ & $p<0,05$ \\
\hline $\begin{array}{c}\text { метание набивного мяча } \\
\text { (3 кг) из-за головы (м) }\end{array}$ & $8,4 \pm 0,16$ & $9,8 \pm 0,75$ & $9,4 \pm 0,56$ & $12,3 \pm 0,45$ & $9,3 \pm 0,97$ & $10,8 \pm 0,65$ & $p<0,05$ \\
\hline 6-минутный бег (м) & $2055,00 \pm 11,08$ & $\begin{array}{c}2287,00 \pm \\
12,24\end{array}$ & $2091,56 \pm 11,45$ & $\begin{array}{c}2445,51 \pm \\
15,20\end{array}$ & $2195,14 \pm 14,28$ & $\begin{array}{c}2241,40 \pm \\
12,65\end{array}$ & $p<0,05$ \\
\hline $\begin{array}{c}\text { поднимание туловища из } \\
\text { положения лежа } \\
\text { за } 30 \text { с (кол- во раз) } \\
\end{array}$ & $24,3 \pm 0,62$ & $26,3 \pm 0,71$ & $27,8 \pm 0,14$ & $32,0 \pm 0,41$ & $27,6 \pm 0,49$ & $29,0 \pm 0,50$ & $p<0,05$ \\
\hline \multicolumn{8}{|c|}{ Девочки } \\
\hline бег $30 \mathrm{~m}(\mathrm{c})$ & $6,17 \pm 0,31$ & $5,95 \pm 0,14$ & $6,77 \pm 0,1$ & $5,55 \pm 0,04$ & $5,76 \pm 0,26$ & $5,72 \pm 0,24$ & $p<0,05$ \\
\hline челночный бег 3 ×30 (c) & $28,24 \pm 0,74$ & $27,95 \pm 0,48$ & $25,84 \pm 0,13$ & $22,75 \pm 0,13$ & $23,91 \pm 0,41$ & $22,23 \pm 0,16$ & $p<0,05$ \\
\hline $\begin{array}{c}\text { наклон вперед } \\
\text { из исходного } \\
\text { положения сидя (см) }\end{array}$ & $12,00 \pm 0,73$ & $14,84 \pm 0,68$ & $11,00 \pm 0,33$ & $14,54 \pm 0,60$ & $12,07 \pm 0,88$ & $13,01 \pm 0,81$ & $p<0,05$ \\
\hline $\begin{array}{c}\text { метание набивного мяча } \\
\text { (3 кг) из-за головы (м) }\end{array}$ & $6,2 \pm 0,44$ & $7,9 \pm 0,67$ & $8,8 \pm 0,23$ & $10,1 \pm 0,44$ & $8,9 \pm 0,48$ & $9,2 \pm 0,25$ & $p<0,05$ \\
\hline 6-минутный бег (м) & $2018,12 \pm 10,02$ & $\begin{array}{c}2224,54 \pm \\
14,18 \\
\end{array}$ & $1998,12 \pm 12,62$ & $\begin{array}{c}2462,54 \pm \\
18,80 \\
\end{array}$ & $2113,25 \pm 14,61$ & $\begin{array}{c}2242,54 \pm \\
16,16 \\
\end{array}$ & $p<0,05$ \\
\hline $\begin{array}{l}\text { сгибание туловища } \\
\text { из положения лежа } \\
\text { за } 30 \text { с (кол- во раз) }\end{array}$ & $21,12 \pm 0,33$ & $24,58 \pm 0,48$ & $23,6 \pm 0,18$ & $26,4 \pm 0,17$ & $25,8 \pm 0,66$ & $26,5 \pm 0,45$ & $p<0,05$ \\
\hline
\end{tabular}

Таблица 2.

Показатели уровня физической подготовленности у детей до и после проведения эксперимента (\%)

\begin{tabular}{|c|c|c|c|c|c|c|c|c|}
\hline \multirow{3}{*}{$\begin{array}{c}\text { Показатели } \\
\text { уровня }\end{array}$} & \multicolumn{4}{|c|}{ ЭГ } & \multicolumn{4}{|c|}{ КГ } \\
\hline & \multicolumn{2}{|c|}{ Мальчики } & \multicolumn{2}{|c|}{ Девочки } & \multicolumn{2}{|c|}{ Мальчики } & \multicolumn{2}{|c|}{ Девочки } \\
\hline & до & после & до & после & до & после & до & после \\
\hline Отличный $(>0,75)$ & 25 & 38 & 20 & 42 & 26 & 26 & 26 & 28 \\
\hline Хороший $(0,5-0,74)$ & 71 & 62 & 78 & 58 & 70 & 74 & 72 & 72 \\
\hline Удовлетворительный $(0,25-0,49)$ & 4 & - & 2 & - & 2 & - & 2 & - \\
\hline Неудовлетворительный $(<0,25)$ & - & - & - & - & - & - & - & - \\
\hline
\end{tabular}

У детей КГ после эксперимента среди мальчиков полностью исчез удовлетворительный уровень физической подготовленности, несколько повысился хороший уровень - с 70\% до 74\%. Количество детей с отличным уровнем физической подготовленности после проведения эксперимента остался неизменным $-26 \%$.

Среди девочек КГ уровень физ. подготовленности распределился следующим образом: отличный уровень подрос с $26 \%$ до $28 \%$, хороший - также и остался на уровне $72 \%$, детей с удовлетворитель- ным уровнем развития физ. подготовленности после проведения эксперимента не осталось.

Динамика показателей и двигательных тестов отражена в таблице 3.

Анализ двигательных тестов выявил значительное улучшение показателей среди детей из экспериментальной группы и достоверно значимые различия с показателями детей из контрольной группы.

После проведения эксперимента дети из экспериментальной группы значительно лучше по 


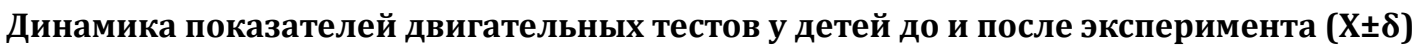

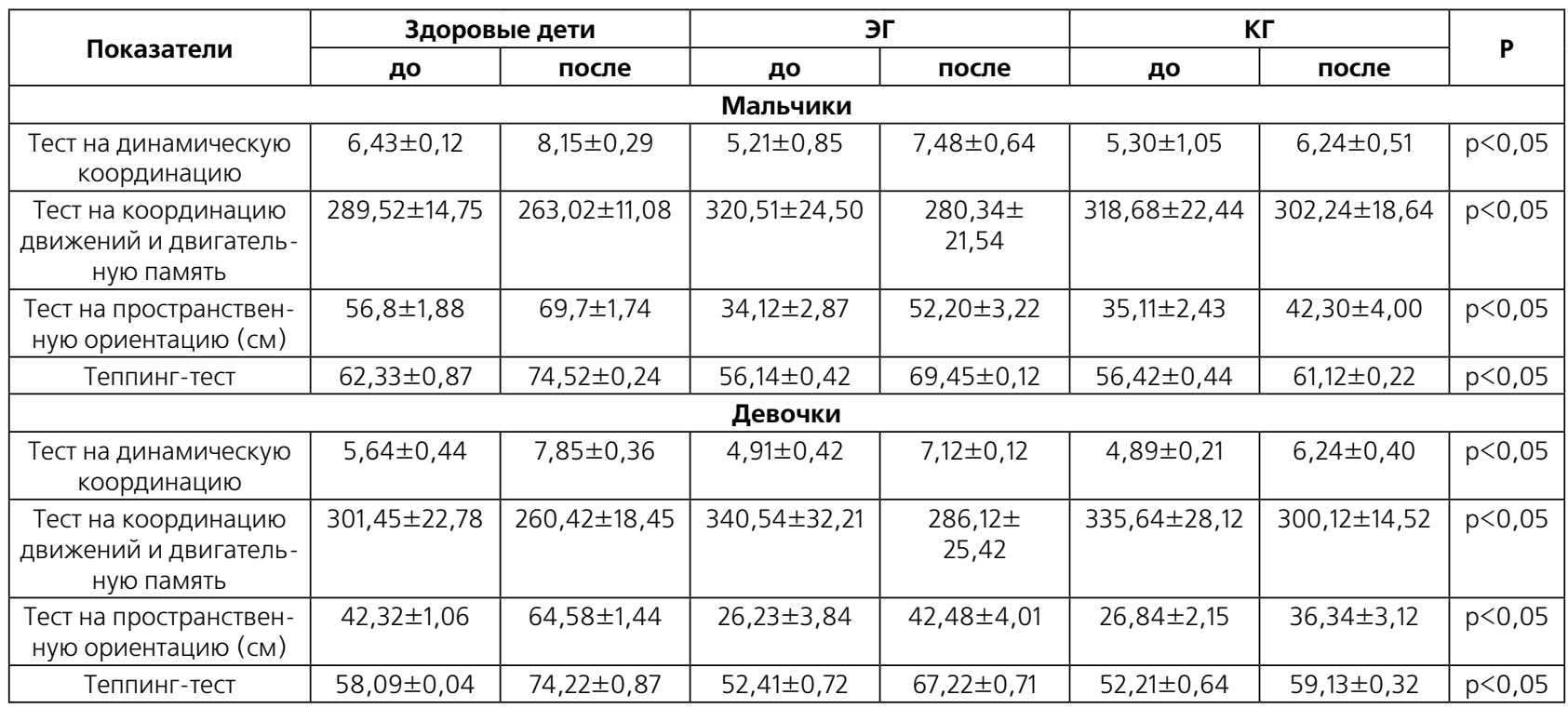

сравнению с детьми из контрольной группы имели динамическую и пространственную ориентации, а также двигательную память, что, в свою очередь, значительно улучшило показатели теппинг-теста.

Нами было выявлено, что уровни, ответственные за координационные и пространственные движения у детей экспериментальной группы почти приблизились к границе физиологической нормы для нормально видящих детей, что свидетельствовало об эффективности проведенного эксперимента.

Также после выполнения эксперимента у детей как экспериментальной, так и контрольной групп еще более повысилась концентрация внимания и снизилось количество совершаемых ошибок до 0,04-0,02 ошибок, что значительно меньше по сравнению с нормально видящими детьми.

Анализ результатов теппинг-теста показал после проведения эксперимента достоверно значимые различия между детьми экспериментальной и контрольной групп и значительное преобладание в экспериментальной группе среднего уровня функционального состояния нервной системы (до 80\% случаев), в 15\% случаев имел место сильный тип нервной системы, и в 5\% случаев - слабый. Тогда как в контрольной группе после проведения эксперимента так и остались в преобладающем большинстве дети со слабым типом нервной системы - 50\% случаев, со средним типом - 46\% случаев и с сильным типом нервной системы - 4\%.
С одной стороны наличие детей со слабым типом нервной системы свидетельствует о низкой работоспособности, быстрым развитием охранительного торможения при действии раздражителей. Фактором риска является и то, что слабая нервная система быстро истощается. В то же время следует отметить, что наличие детей со слабой нервной системой реально еще не означает ухудшения спортивного результата. Слабая нервная система обладает большей чувствительностью, реагируя даже на самые слабые раздражители.

Поскольку уровень активации в покое у детей со слабой нервной системой выше, чем у детей с сильной нервной системой, они ближе к пороговому уровню реагирования и быстрее его достигнут при действии сигнала (одинакового по интенсивности для всех испытуемых). Даная особенность детей со слабой нервной системой обеспечивает их успешность на старте.

Выводы. Таким образом, анализируя динамику показателей физической подготовленности и двигательных тестов детей со слабой степенью миопии и спазмом аккомодации, можно утверждать о положительном влиянии применяемой программы на повышение функциональных возможностей органов дыхания и кровообращения, а также адаптационных резервов сердечно-сосудистой и дыхательной систем. 


\section{Психология и психотехника 7(70) • 2014}

\section{Список литературы:}

1. Аветисов Э.С. Близорукость. 2-е изд., перераб. и доп. М., 2002. 284 с.

2. Ахмадуллина И.А. Физическое воспитание слабовидящих учащихся среднего специального учебного заведения: автореф. дисс. ... канд. пед. наук. Набережные Челны, 2011. 255 с.

3. Балашова Н.Н., Левшина Г.П. и др. Допустимые уровни тренировочных и соревновательных нагрузок для учащихся учебно-тренировочных групп ДЮСШ и СДЮСШОР: Методические рекомендации. М., 1989. 22 c.

4. Никитушкин В.Г., Квашук П.В., Бауэр В.Г. Организационно-методические основы подготовки спортивного резерва. М.: Советский спорт, 2005. 232 с.

5. Deng L., Gwiazda J., Manny R.E., Scheiman M., Weissberg E., Fern K.D., Weise K. Limited change in anisometropia and aniso-axial length over 13 years in myopic children enrolled in the correction of myopia evaluation trial. / Invest Ophthalmol Vis Sci. 2014 Apr 3;55(4):2097-105.

6. $\quad$ Lin Z., Vasudevan B., Jhanji V., Gao T.Y., Wang N.L., Wang Q., Wang J., Ciuffreda K.J., Liang Y.B. Eye exercises of acupoints: their impact on refractive error and visual symptoms in Chinese urban children / BMC Complement Altern Med. 2013. Nov 7;13:306.

7. Myrowitz E.H. Juvenile myopia progression, risk factors and interventions. Saudi J. Ophthalmol. 2012. Jul;26(3):293-7.

8. Walline J.J., Lindsley K., Vedula S.S., Cotter S.A., Mutti D.O., Twelker J.D. Interventions to slow progression of myopia in children / Cochrane Database Syst Rev. 2011. Dec 7;(12):CD004916.

\section{References (transliteration):}

1. Avetisov, E.S. Blizorukost'. 2-e izd., pererab. i dop. M., 2002. 284 s.

2. Akhmadullina, I.A. Fizicheskoe vospitanie slabovidyashchikh uchashchikhsya srednego spetsial'nogo uchebnogo zavedeniya: avtoref. diss. ... kand. ped. nauk. Naberezhnye Chelny, 2011. 255 s.

3. Balashova H.H., Levshina G.P. i dr. Dopustimye urovni trenirovochnykh i sorevnovatel'nykh nagruzok dlya uchashchikhsya uchebno-trenirovochnykh grupp DYuSSh i SDYuSShOR: Metodicheskie rekomendatsii. M., 1989. $22 \mathrm{~s}$.

4. Nikitushkin V.G., Kvashuk P.V., Bauer V.G. Organizatsionno-metodicheskie osnovy podgotovki sportivnogo rezerva. M.: Sovetskii sport, 2005. 232 s.

5. Deng L., Gwiazda J., Manny R.E., Scheiman M., Weissberg E., Fern K.D., Weise K. Limited change in anisometropia and aniso-axial length over 13 years in myopic children enrolled in the correction of myopia evaluation trial. / Invest Ophthalmol Vis Sci. 2014 Apr 3;55(4):2097-105.

6. Lin Z., Vasudevan B., Jhanji V., Gao T.Y., Wang N.L., Wang Q., Wang J., Ciuffreda K.J., Liang Y.B. Eye exercises of acupoints: their impact on refractive error and visual symptoms in Chinese urban children / BMC Complement Altern Med. 2013. Nov 7;13:306.

7. Myrowitz E.H. Juvenile myopia progression, risk factors and interventions. Saudi J. Ophthalmol. 2012. Jul;26(3):293-7.

8. Walline J.J., Lindsley K., Vedula S.S., Cotter S.A., Mutti D.O., Twelker J.D. Interventions to slow progression of myopia in children / Cochrane Database Syst Rev. 2011. Dec 7;(12):CD004916. 